\title{
RARE CASE OF FETAL ADENOCARCINOMA OF LUNG.
}

Kapil Panchbhai, P. B. Nichkawade, Nilesh Tulaskar, Abhay Choudhary, Rohan umalkar

1. Assistant Professor, General Surgery, NKP Salve Medical College\& Reaserch Centre, Lata Mangeshkar Hospital,

2. Associate Professor, General Surgery, NKP Salve Medical College\& Reaserch Centre, Lata Mangeshkar Hospital,

3. Assistant Professor, General Surgery, NKP Salve Medical College\& Reaserch Centre, Lata Mangeshkar Hospital,

4. Assistant Professor, General Surgery, NKP Salve Medical College\& Reaserch Centre, Lata Mangeshkar Hospital,

5. Junior Resident, General Surgery, NKP Salve Medical College\& Reaserch Centre, Lata Mangeshkar Hospital.

\section{CORRESPONDING AUTHOR:}

Dr. Kapil Panchbhai,

Flat no 10, plot no 8, A. D. Bhavan, Great nag road,

Mahaveer nagar , Nagpur,

Maharashtra- 440009.

E-mail: k_panchbhai@rediffmail.com

Well-differentiated fetal adenocarcinoma (WDFA) is a very uncommon malignant tumor originating in the lung. We report the case of a 26- year- old male with a chance detection at chest x-ray of a well defined mass in the right lower lobe during a medical examination. The patient was suffered from a flu syndrome, with cough and fever. He was a nonsmoker. Computed Tomography scan showed large growth at right lower lobe with intra bronchial component in superior and medial, basal segment bronchi with no mediastinal lymphadenopathy. CT Guided FNAC report s/o Neuroendocrine tumor (likely to be carcinoid). He underwent bronchoscopy which shows vascular growth at right lower lobe. Right posterolateral thoracotomy with lower lobectomy was performed. A pathologic diagnosis of well differentiated fetal adenocarcinoma of the lung was made. Fetal Adenocarcinoma is a rare tumor, with a relative incidence estimated to be no more than $0.5 \%$ of all lung cancers. Few cases of this type of malignancy were reported in literature.

INTRODUCTION: Fetal adenocarcinoma (FA) of the lung is a rare subtype of pulmonary adenocarcinoma that exhibits tissue architecture and cell characteristics that resemble fetal lung tissue upon microscopic examination. It is currently considered a variant of solid adenocarcinoma with mucin production (1). FA is a rare tumor, with a relative incidence estimated to be no more than $0.5 \%$ of all lung cancers $(2,3,4,5)$. FA can produce repeated hemoptysis, possibly related to cavitation of the tumor (2). Other presenting symptoms described have included: flu-like syndrome with cough and fever (6). There is no protocol for treatment due to the rarity of the case. Complete surgical resection is the treatment of choice in FA, as it is in nearly all forms of lung cancer (7). Mediastinal Lymphadenectomy/ Sampling should be done. It is reported that chemotherapy or radiotherapy has seldom been effective (8). Case reports suggest that chemotherapy with UFT (tegafur + uracil) may be useful in FA (8).

CASE REPORT :A case of 26 yrs old male, non smoker presented with complaints of recurrent fever with flu like symptoms about 4 months duration. He was evaluated by chest physician.. 
Patient was on AKT therapy since 3month. On physical examination, the patient was completely normal. On Respiratory examination, air entry decreased in right lower lobe.

Chest x-ray was done which s/o well-defined mass in the right upper lobe during a medical examination (Fig. 1) He underwent HRCT chest which was s/o large growth at right lower lobe with intra bronchial component in superior and medial, basal segment bronchi with possibilities of primary lung neoplastic lesion with no mediastinal lymphadenopathy. (Fig. 2)

CT Guided FNAC report s/o Neuro-endocrine tumor (likely to be carcinoid). He underwent bronchoscopy which shows vascular growth at right lower lobe. Bronchial biopsy was taken shows bronchial mucosa with non specific inflammation.

Patient was taken up for open surgical procedure. Right posterolateral thoracotomy with lower lobectomy. Operative findings were large growth in right lower lobe of size $7 \times 4 \times 4$, lobulated, hard, extending to Right lobe bronchus. Post operative period was uneventful.

Histopathology of the surgical specimen was reported as Non small Cell Carcinoma with Neuroendocrine Feature. Second opinion taken from Tata Memorial Hospital was suggestive of Well differentiated Fetal adenocarcinoma type (WDFA; WHO 2002). Immunohistochemistry shows chromogranin, Desmin, \& other markers positive.

DISCUSSION: Well differentiated fetal adenocarcinoma is a rare type of lung tumor, first described by Koss et al. in 1991 (9). It appears as a fetal lung at 10 to 15 weeks of gestation, resembling pulmonary blastoma, but the adjacent mesenchymal tissue is histologically benign (10). Recent WHO 2002 classification removed WDFA tumours from the pulmonary blastoma category and classified them as a variant of adenocarcinoma (11). No specific immunohistochemical pattern has been described for this tumor type.

WDFA occur at any age, with the mean age at diagnosis being 35 to 40 years and gender ratio favoring women or equal in distribution. FA is exceptionally rare in children. However, several case reports have involved FA's in pregnant women or the early postnatal period.

The prognosis of patients with FA as a whole is considered to be better than that of most other forms of non-small cell carcinoma, including biphasic pulmonary blastoma. According to the previous study, the 10 year survival for WDFA is about $75 \%$ versus about $15 \%$ for BPB $(12,13)$. Based on current information about the disease, no additional treatment was recommended and the patient was discharged. Follow up is planned for every 3 months for the first year, than every 6 months from the second to the fifth year, and then annually.

CONCLUSION: WDFA of the lung is a rare tumour. It is Important to identify this rare variant of adenocarcinoma because it is a low grade malignancy with low associated mortality. Complete surgical excision is the treatment of choice and less responsive to Chemotherapy and radiotherapy.

\section{REFERENCES:}

1. Travis WD, Brambilla E, Muller-Hermelink HK, Harris CC (Eds.): World Health Organization Classification of Tumours. Pathology and Genetics of Tumours of the Lung, Pleura, Thymus and Heart. IARC Press: Lyon 2004. 
2. Thompson RJ, Hasleton PS, Taylor PM, Woodhead M, Byrd LM. Haemoptysis in pregnancy caused by a well-differentiated fetal adenocarcinoma: a case report. J Med Case Rep 2010; $4: 17$.

3. Luo DL, Liu YH, Zhuang HG, Liao RQ, Luo XL, Xu FP, Zhang F. [Clinicopathologic study of pulmonary adenocarcinoma with features of bronchioloalveolar carcinoma]. Zhonghua Bing Li Xue Za Zhi 2008; 37:737-42. [Article in Chinese] [Abstract].

4. Esper A, Force S, Gal A, Wolfenden LL. A 36-year-old woman with hemoptysis and a lung mass 3 months after delivery. Chest 2006; 130:1620-3.

5. Cutler CS, Michel RP, Yassa M, Langleben A. Pulmonary blastoma: case report of a patient with a 7-year remission and review of chemotherapy experience in the world literature. Cancer 1998;82:462-7

6. Longo M, Levra MG, Capelletto E, Billè A, Ardissone F, Familiari U, Novello S. Fetal adenocarcinoma of the lung in a 25-year-old woman. J Thorac Oncol 2008; 3:441-3.

7. Fujino S, Asada Y, Konishi T, Asakura S, Kato H, Mori A. Well-differentiated fetal adenocarcinoma of lung. Lung Cancer 1995; 13:311-6.

8. Matsuoka T, Sugi K, Matsuda E, Umemori Y, Okabe K, Hirasawa K, Azuma T. [Clear cell adenocarcinoma with a component of well-differentiated fetal adenocarcinoma; report of a case] Kyobu Geka 2006;59:867-70. [Article in Japanese].

9. Koss MN, Hochholzer L, O’Leary T, et al. Pulmonary blastomas. Cancer 1991; 67: 23682381.

10. Nakatani $Y$, Kitomura H, Inayama $Y$, et al. Pulmonary adenocarcinoma of the fetal lung type. Am J Surg Patho 1998; 22:399-411.

11. Colby TV, Adenocarcinoma. In: travis WD, Brambila E, Harris CC. WHO classification of Tumours: Tumors of the Lung, pleura,thymus and Heart.Lyon: IARC Press, 2004. Pg 35-44.

12. Sato S, Koike T, Yamato Y, Yoshiya K, Honma K, Tsukada H. Resected well-differentiated fetal pulmonary adenocarcinoma and summary of 25 cases reported in Japan. Jpn J Thorac Cardiovasc Surg 2006; 54:539-42.

13. Rossi G, Marchioni A, Sartori1 G, Longo L, Piccinini S, Cavazza A. Histotype in non-small cell lung cancer therapy and staging: The emerging role of an old and underrated factor. Curr Resp Med Rev 2007; 3: 69-77. 


\section{CASE REPORT}

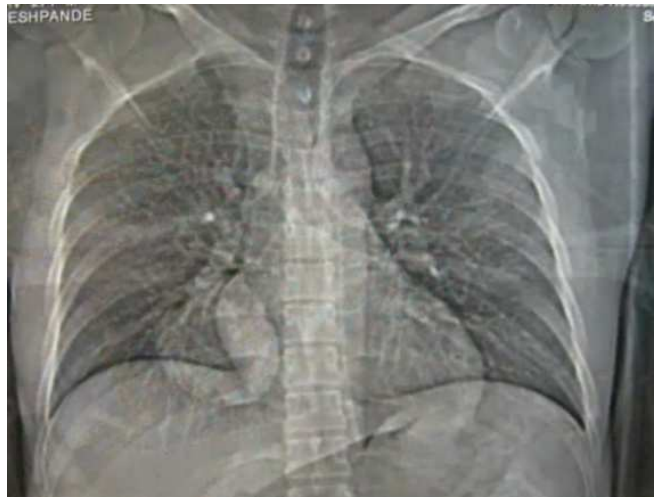

Fig 1: Shows well defined mass in right lower lobe of Lung.

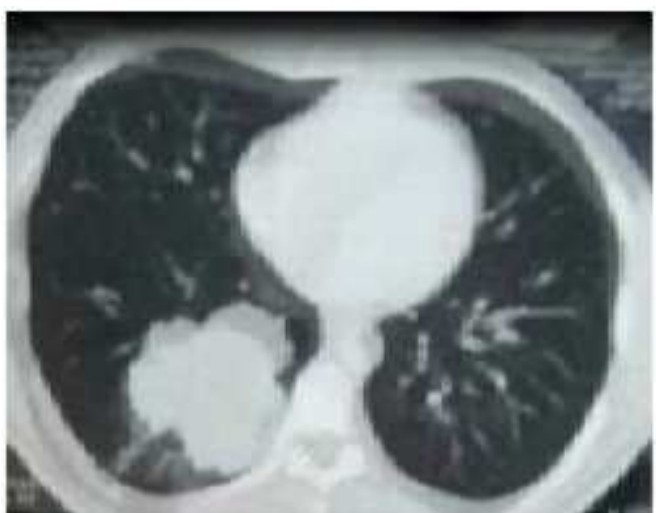

Fig 2: CT ThoraxLarge growth at right lower lobe with intra Bronchial Component.

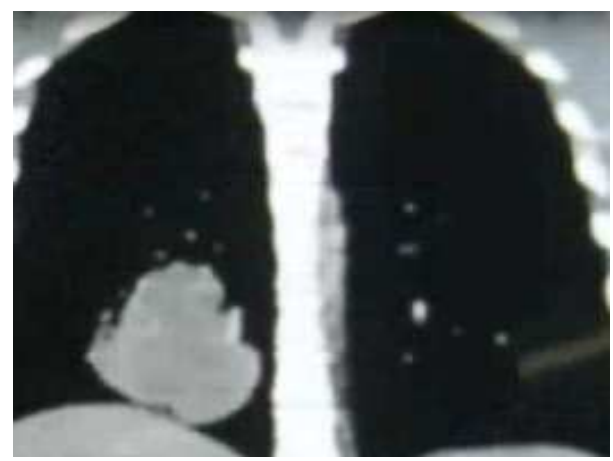

Fig. 3 :CT Thorax Shows well defined mass in right lower lobe of lung. 


\section{CASE REPORT}

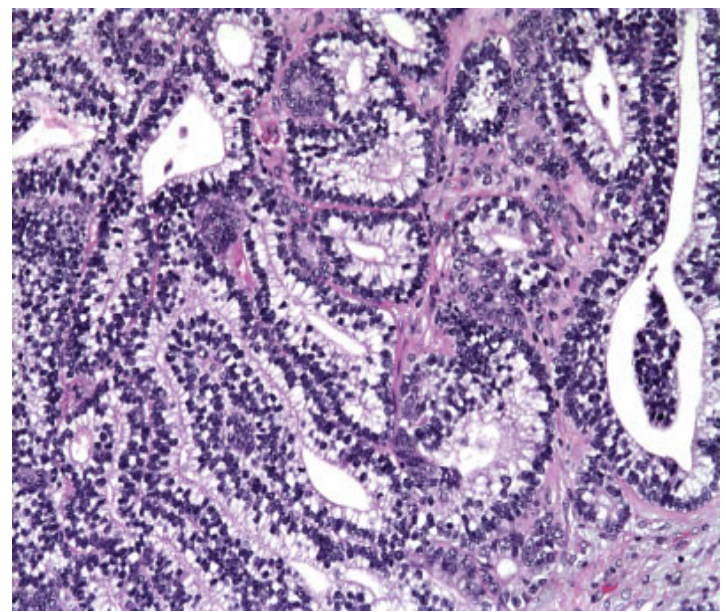

Fig. The histological appearance of well differentiated fetal adenocarcinoma

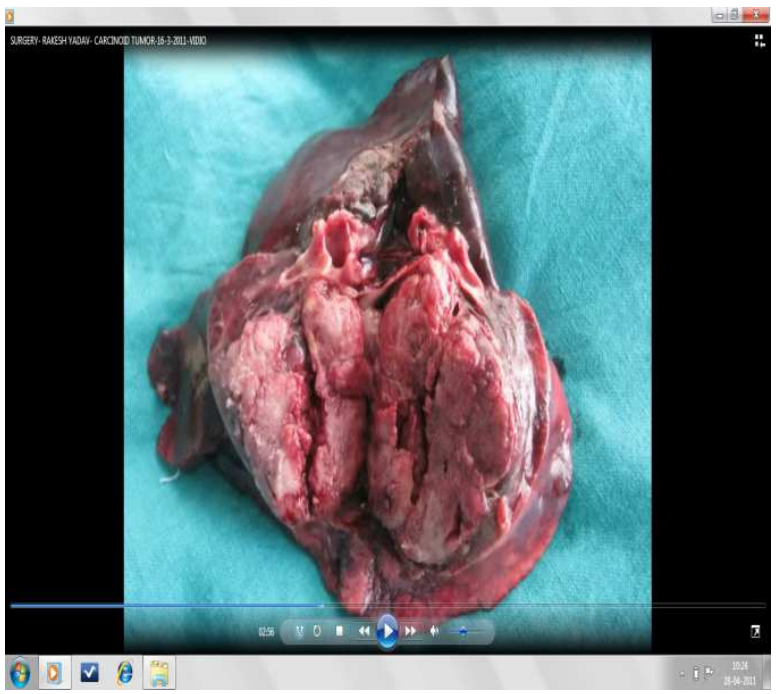

Fig. resected specimen of fetal adenocarcinoma of lung 